\title{
Portal and peripheral blood short chain fatty acid concentrations after caecal lactulose instillation at
} surgery

\author{
S G Peters, E W Pomare, C A Fisher
}

\begin{abstract}
The major end products of fermentation, short chain fatty acids (acetate, propionate, butyrate) were measured in portal and peripheral venous blood after the caecal instillation of lactulose at surgery in patients undergoing elective cholecystectomy. Blood samples for short chain fatty acid measurement were taken before and at 15 minute intervals up to 60 minutes after caecal instillation of either $20 \mathrm{ml}$ sterile saline or $6.7 \mathrm{~g}$ or $10 \mathrm{~g}$ lactulose. Fasting concentrations $(\mathbf{n}=28)$ were $(\mu \mathrm{mol} / 1$, mean (SD)); portal acetate $128.0(\mathbf{7 0 . 8 )}$, propionate $34.4(23.3)$, butyrate $17.6(18.4)$; peripheral acetate $67.0(23.0)$, propionate $3.7(1.2)$, butyrate traces only. After lactulose there was a rapid rise in portal short chain fatty acids with peak concentrations being reached in 15 to 45 minutes. Mean peak concentrations $(\mu \mathrm{mol} / \mathrm{l}$ (SD)) after $10 \mathrm{~g}$ lactulose were acetate 240.9 $(142 \cdot 2)$, propionate $39.0(17 \cdot 8)$ and butyrate $26.9(17 \cdot 6)$. The changes in acetate concentrations seen in portal blood were reflected in peripheral blood acetate measurements. In contrast with portal blood, only small amounts of propionate and traces of butyrate were found in peripheral blood.

(Gut 1992; 33: 1249-1252)
\end{abstract}

The principal end products of fermentation are the short chain fatty acids acetate, propionate and butyrate and the gases carbon dioxide, methane and hydrogen.' In ruminants and other herbivores short chain fatty acids contribute substantially to basal energy requirements, while in man there have been few studies investigating the fate of these acids. ${ }^{3}$

There are many lines of evidence now which suggest that fermentation occurs in the human colon and that absorption of the resultant short chain fatty acids is rapid and contributes significantly to portal and peripheral blood short chain fatty acid concentrations. ${ }^{13}$ The major short chain fatty acid, acetate, is also an important metabolic fuel and in species such as the rat, falling portal blood levels trigger active liver production of acetate..$^{+5}$

Studies of the fermentation process in man and the fate of its short chain fatty acid end products have been limited by the inaccessibility of both the large bowel and the portal venous system. We have therefore attempted to establish in the present study not only that fermentation occurs in the human caecum but that short chain fatty acids are rapidly absorbed into the portal venous circulation and beyond by measuring short chain fatty acids in portal and peripheral blood after the caecal instillation of the fermentable carbohydrate lactulose in patients undergoing elective cholecystectomy.

\section{Methods}

PATIENTS

Twenty eight patients ( 23 female, five male) in normal health, average age $47 \cdot 6(15 \cdot 7)$ years (range 23-74) undergoing elective cholecystectomy for gall stones were randomly allocated to three groups. In two groups lactulose was injected into the caecum at surgery and in the third group sterile saline. Patients were maintained on polysaccharide free food for 24 hours before operation and none had taken antibiotics in the three months before surgery.

\section{SAMPLING}

Caecal injections and portal vein samplings were done by a senior surgeon and no patient suffered any ill effects as a result of these procedures. No operation was prolonged to allow additional portal blood samples to be taken. Peripheral venous blood samples were taken for up to two hours. All samples were collected into heparinised tubes, mixed and the plasma separated by centrifugation for 10 minutes at $1600 \mathrm{~g}$.

\section{Short chain fatty acid measurement}

Short chain fatty acid concentrations were measured in duplicate plasma samples by a modification of the method described by Pomare et $a l^{3}$ which utilises a vacuum transfer technique followed by gas chromatography. Plasma was first deproteinised with an equal volume of 0.36 $\mathrm{mol} / \mathrm{l}$ perchloric acid, centrifuged at $1600 \mathrm{~g}$ for 15 minutes and the supernatant retained and stored at $-20^{\circ} \mathrm{C}$ until analysed. At a later date an aliquot of the thawed supernatant (equivalent to $1 \mathrm{ml}$ plasma) was mixed with $50 \mu \mathrm{l} 2 \cdot 7 \mathrm{mmol} / \mathrm{l}$ isobutyric acid (internal standard) and vacuum distilled. When the distillation process was completed (60-90 minutes) the distillate was thawed at room temperature, mixed and refrozen in liquid nitrogen before being freeze dried. Immediately before gas chromatographic analysis $100 \mu \mathrm{l}$ of $3.33 \mathrm{~mol} / \mathrm{l}$ phosphoric acid was added to the dried sample and $1 \mu \mathrm{l}$ injected onto the column.

\section{CHROMATOGRAPHY}

A Varian 3700 gas chromatograph (Varian Instrument Group, Sunnyvale, California 94089, 
USA) with a flame ionisation detector was fitted with a $2 \mathrm{~m} \times 2 \mathrm{~mm}$ internal diameter glass column packed with phosphoric acid treated Tenax GC, 80-100 mesh. The columns were conditioned at $150^{\circ} \mathrm{C}$ for two to three days before use. The analyses were performed isothermally at $140^{\circ} \mathrm{C}$. The injector and detector temperatures were $200^{\circ} \mathrm{C}$ and the carrier gas nitrogen at a rate of 30 $\mathrm{ml} / \mathrm{min}$. Short chain fatty acid concentrations were calculated relative to the internal standard by the peak height ratio method and all results given as the mean (1) standard deviation.

\section{STATISTICAL ANALYSIS}

Data were analysed using the Kruskal-Wallis one way analysis of variance and the MannWhitney U Test. ${ }^{6}$

\section{ETHICS}

Permission for this study was obtained from the Wellington Hospital Board Research Ethical Committee.

\section{Results}

\section{FASTING SHORT CHAIN FATTY ACID} CONCENTRATIONS

The fasting short chain fatty acid concentrations in both portal and peripheral venous plasma are shown in Table I. There was a wide interindividual variation in fasting short chain fatty acid concentrations in portal and peripheral blood. There was also a marked difference between portal and peripheral fasting short chain fatty acid concentrations, particularly propionate (peripheral approximately $10 \%$ portal) and butyrate (virtually undetected in peripheral

Individual peak portal and peripheral acetate concentrations ( $\mu \mathrm{mol} / \mathrm{l})$ following: $10 \mathrm{~g}$ lactulose $(n=10), 6.7$ glactulose $(n=6), \boldsymbol{\Delta} 20 \mathrm{ml}$ sterile saline $(n=12)$. Horizontal line indicates mean, vertical bars indicate (1SD).

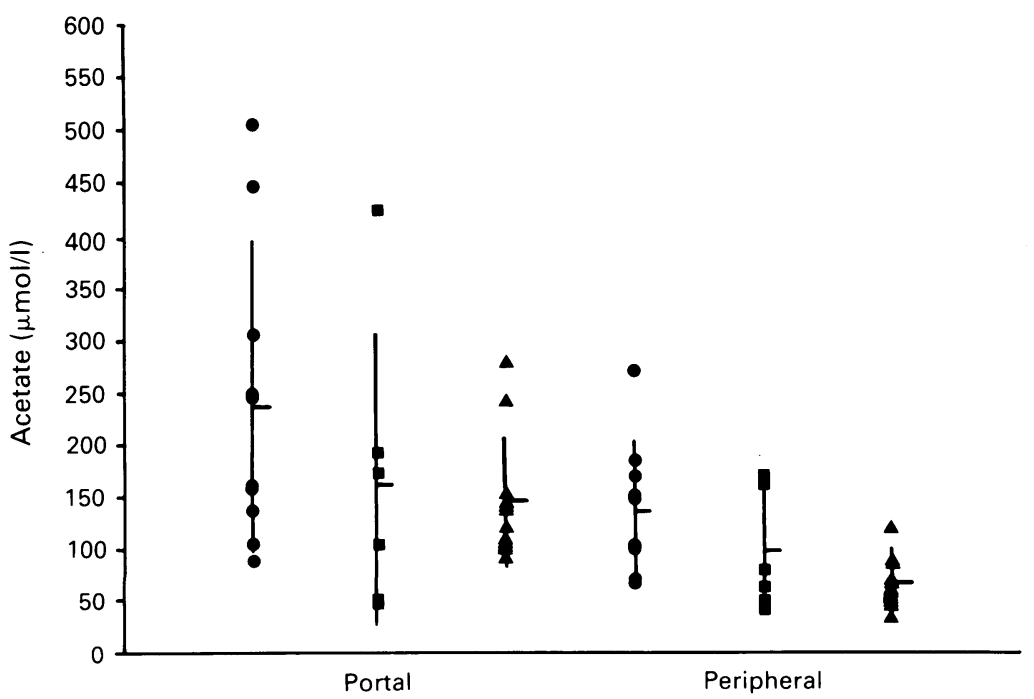

plasma). There were no statistically significant differences between the three study groups for fasting portal or fasting peripheral short chain fatty acid concentrations of acetate, propionate and butyrate.

\section{PORTAL SHORT CHAIN FATTY ACID} CONCENTRATIONS

Peak portal acetate concentrations are shown in the Figure. Ten grams lactulose produced peak portal concentrations $(\mu \mathrm{mol} / \mathrm{l}$, mean $(\mathrm{SD}))$ of $240.9(142 \cdot 2), 39.0(17 \cdot 8)$, and $26.9(17 \cdot 6)$ respectively for acetate, propionate and butyrate; $6.7 \mathrm{~g}$ lactulose produced peak portal concentrations $(\mu \mathrm{mol} / 1$, mean $(\mathrm{SD}))$ of $166.4(140 \cdot 7)$, $30.9(18.4)$, and $22.4(23.5)$ respectively for acetate, propionate and butyrate. This compares with peak portal concentrations $(\mu \mathrm{mol} / \mathrm{l}$, mean (SD)) of $144 \cdot 0(58 \cdot 5), 37 \cdot 6(21 \cdot 1)$, and $23 \cdot 1$ $(17 \cdot 0)$ respectively for acetate, propionate and butyrate after sterile saline. There were no statistically significant differences between peak portal short chain fatty acid concentrations after $10 \mathrm{~g}$ or $6.7 \mathrm{~g}$ lactulose or sterile saline. With regard to peak portal acetate concentrations, however, $6.7 \mathrm{~g}$ lactulose was associated with a $15 \cdot 6 \%$ increase and $10 \mathrm{~g}$ lactulose with a $67 \cdot 3 \%$ increase above the peak portal acetate concentrations after sterile saline. The difference between fasting portal concentrations and peak portal concentrations of acetate (mean (SD), $111 \cdot 1(116 \cdot 8) \mu \mathrm{mol} / \mathrm{l})$ was statistically significant after $10 \mathrm{~g}$ lactulose compared with sterile saline (mean (SD), 12.9 (77.1) $\mu \mathrm{mol} / \mathrm{l})(\mathrm{p}<0 \cdot 05)$

The results of portal short chain fatty acid measurements after the caecal injection of lactulose and sterile saline are shown in Table II. Lactulose produced a rapid rise in portal acetate with peak concentrations reached at 15 to 45 minutes. The $6.7 \mathrm{~g}$ dose of lactulose appeared to be completely fermented in 30 to 45 minutes with portal short chain fatty acid concentrations back to or below fasting levels in all but one subject at 45 minutes. After $10 \mathrm{~g}$ lactulose, portal short chain fatty acid concentrations were still raised at 45 minutes in all subjects. Peak portal short chain fatty acid concentrations were measured at similar times which indicated that both doses of lactulose were rapidly fermented, however, the fermentation of the larger $10 \mathrm{~g}$ dose of lactulose appeared more prolonged.

TABLE II Short chain fatty acid concentrations in portal plasma $(\mu \mathrm{mol} / \mathrm{l})^{\star}$

\begin{tabular}{|c|c|c|c|c|}
\hline \multicolumn{2}{|l|}{ Time } & Acetate & Propionate & Butyrate \\
\hline \multicolumn{5}{|c|}{$10 \mathrm{~g}$ Lactulose } \\
\hline Fasting & $(n=10)$ & $129 \cdot 7(92 \cdot 5)$ & $25 \cdot 6(14 \cdot 4)$ & $11 \cdot 2(7 \cdot 6)$ \\
\hline $15 \mathrm{~min}$ & $(\mathrm{n}=9)$ & $164 \cdot 2(142 \cdot 9)$ & $27 \cdot 7(19 \cdot 0)$ & $17 \cdot 1(17 \cdot 4)$ \\
\hline $30 \mathrm{~min}$ & $(\mathrm{n}=9)$ & $170.8(91.9)$ & $27 \cdot 5(6 \cdot 4)$ & $17 \cdot 3(12 \cdot 3)$ \\
\hline $45 \mathrm{~min}$ & $(n=6)$ & $197 \cdot 2(150 \cdot 7)$ & $25 \cdot 7(16 \cdot 4)$ & $15 \cdot 4(12 \cdot 7)$ \\
\hline \multicolumn{5}{|c|}{ 6.7 Lactulose } \\
\hline Fasting & $(n=6)$ & $120 \cdot 1(47 \cdot 8)$ & $39 \cdot 2(12 \cdot 6)$ & $16 \cdot 6(8 \cdot 7)$ \\
\hline $15 \mathrm{~min}$ & $(n=6)$ & $146 \cdot 0(141 \cdot 8)$ & $26 \cdot 6(14 \cdot 8)$ & $13.6(11.4)$ \\
\hline $30 \mathrm{~min}$ & $(n=5)$ & $139.5(78.6)$ & $25 \cdot 2(20 \cdot 7)$ & $17 \cdot 4(17 \cdot 2)$ \\
\hline $45 \mathrm{~min}$ & $(n=4)$ & $96 \cdot 2(69 \cdot 8)$ & $22 \cdot 3(15 \cdot 1)$ & $19 \cdot 9(26 \cdot 3)$ \\
\hline $60 \mathrm{~min}$ & $(n=3)$ & $110 \cdot 4(82 \cdot 5)$ & $20 \cdot 3(16 \cdot 7)$ & $19.6(21.9)$ \\
\hline \multicolumn{5}{|c|}{ Sterile Saline } \\
\hline Fasting & $(n=12)$ & $130 \cdot 6(64 \cdot 8)$ & $39 \cdot 2(31 \cdot 4)$ & $23 \cdot 3(26 \cdot 1)$ \\
\hline $15 \mathrm{~min}$ & $(\mathrm{n}=12)$ & $118 \cdot 2(56 \cdot 6)$ & $30 \cdot 2(18 \cdot 3)$ & $17 \cdot 6(16 \cdot 2)$ \\
\hline $30 \mathrm{~min}$ & $(\mathrm{n}=12)$ & $116 \cdot 3(53 \cdot 5)$ & $32 \cdot 2(21 \cdot 2)$ & $19 \cdot 8(15 \cdot 7)$ \\
\hline $45 \mathrm{~min}$ & $(n=6)$ & $112 \cdot 3(32 \cdot 6)$ & $26 \cdot 5(20 \cdot 7)$ & $19 \cdot 0(18.0)$ \\
\hline
\end{tabular}


TABLE III Short chain fatty acid concentrations in peripheral $\operatorname{plasma}(\mu \mathrm{mol} / \mathrm{l})^{\star}$

\begin{tabular}{llll}
\hline Time & & Acetate & Propionate \\
\hline $10 \mathrm{~g}$ Lactulose & & & \\
Fasting & $(\mathrm{n}=10)$ & $75 \cdot 2(17 \cdot 4)$ & $3 \cdot 5(1 \cdot 2)$ \\
$15 \mathrm{~min}$ & $(\mathrm{n}=9$ & $101 \cdot 5(78 \cdot 2)$ & $3 \cdot 1(0 \cdot 9)$ \\
$30 \mathrm{~min}$ & $(\mathrm{n}=9)$ & $113 \cdot 8(63 \cdot 5)$ & $2 \cdot 9(0 \cdot 5)$ \\
$45 \mathrm{~min}$ & $(\mathrm{n}=6)$ & $106 \cdot 0(67 \cdot 6)$ & $3 \cdot 6(1 \cdot 7)$ \\
$60 \mathrm{~min}$ & $(\mathrm{n}=6)$ & $129 \cdot 7(73 \cdot 8)$ & $3 \cdot 4(1 \cdot 9)$ \\
$120 \mathrm{~min}$ & $(\mathrm{n}=6)$ & $125 \cdot 6(44 \cdot 2)$ & $3 \cdot 8(1 \cdot 8)$ \\
$6 \cdot 7 \mathrm{~g} \mathrm{Lactulose}$ & & & \\
Fasting & $(\mathrm{n}=6)$ & $60 \cdot 8(31 \cdot 6)$ & $3 \cdot 7(1 \cdot 4)$ \\
$15 \mathrm{~min}$ & $(\mathrm{n}=6)$ & $70 \cdot 2(47 \cdot 0)$ & $3 \cdot 2(1 \cdot 4)$ \\
$30 \mathrm{~min}$ & $(\mathrm{n}=5)$ & $77 \cdot 9(34 \cdot 4)$ & $3 \cdot 3(1 \cdot 3)$ \\
$45 \mathrm{~min}$ & $(\mathrm{n}=5)$ & $80 \cdot 7(54 \cdot 4)$ & $3 \cdot 4(1 \cdot 6)$ \\
$60 \mathrm{~min}$ & $(\mathrm{n}=5)$ & $78 \cdot 2(46 \cdot 8)$ & $3 \cdot 3(1 \cdot 6)$ \\
$120 \mathrm{~min}$ & $(\mathrm{n}=6)$ & $67 \cdot 4(48 \cdot 1)$ & $3 \cdot 4(1 \cdot 6)$ \\
Sterile Saline & & & \\
Fasting & $(\mathrm{n}=12)$ & $63 \cdot 2(22 \cdot 3)$ & $3 \cdot 9(1 \cdot 1)$ \\
$15 \mathrm{~min}$ & $(\mathrm{n}=12)$ & $55 \cdot 1(19 \cdot 2)$ & $4 \cdot 0(1 \cdot 7)$ \\
$30 \mathrm{~min}$ & $(\mathrm{n}=12)$ & $55 \cdot 0(14 \cdot 7)$ & $3 \cdot 8(1 \cdot 5)$ \\
$45 \mathrm{~min}$ & $(\mathrm{n}=9)$ & $61 \cdot 3(25 \cdot 5)$ & $3 \cdot 8(1 \cdot 5)$ \\
$60 \mathrm{~min}$ & $(\mathrm{n}=8)$ & $48 \cdot 8(16 \cdot 6)$ & $3 \cdot 7(1 \cdot 9)$ \\
$120 \mathrm{~min}$ & $(\mathrm{n}=9)$ & $49 \cdot 9(12 \cdot 0)$ & $3 \cdot 6(1 \cdot 7)$ \\
\hline \multirow{2}{*}{ mean $(1 \mathrm{SD})$} & & &
\end{tabular}

PERIPHERAL SHORT CHAIN FATTY ACID

CONCENTRATIONS

Peak peripheral acetate concentrations are shown in the Figure. Ten grams lactulose produced peak peripheral concentrations $(\mu \mathrm{mol} / 1$, mean (SD)) of $132 \cdot 4(65 \cdot 0)$ and $4 \cdot 1(1 \cdot 6)$ respectively for acetate and propionate; $6.7 \mathrm{~g}$ lactulose produced peak peripheral concentrations $(\mu \mathrm{mol} / \mathrm{l}$, mean (SD)) of $94 \cdot 7(56 \cdot 6)$, and $4 \cdot 0(1 \cdot 2)$ respectively for acetate and propionate. This compares with peak peripheral concentrations $(\mu \mathrm{mol} / 1$, mean (SD)) of $68.3(21.4)$ and $4.3(1.8)$ respectively for acetate and propionate after sterile saline. No quantifiable amount of butyrate was found in any of the peripheral samples. The difference between peak peripheral acetate concentrations after $10 \mathrm{~g}$ lactulose and sterile saline was statistically significant $(\mathrm{p}<0.05)$, with $10 \mathrm{~g}$ lactulose producing a $93.8 \%$ higher peak peripheral acetate concentration than sterile saline. 6.7 g lactulose was associated with a $38.6 \%$ higher peak peripheral acetate concentration than sterile saline. The difference between fasting and peak peripheral concentrations of acetate (mean (SD), 64.0 (67.7) $\mu \mathrm{mol} / \mathrm{l}$ ) was statistically significant after $10 \mathrm{~g}$ lactulose compared with sterile saline (mean (SD), 7.0 $(13 \cdot 2) \mu \mathrm{mol} / \mathrm{l})(\mathrm{p}<0.05)$.

The results of peripheral short chain fatty acid measurements after caecal injection of lactulose and sterile saline are shown in Table III. The changes seen in peripheral acetate concentrations produced by lactulose (either $10 \mathrm{~g}$ or $6.7 \mathrm{~g}$ ), were smaller and slightly less rapid when compared with the changes in portal acetate concentrations. The pattern of change for acetate, however, was similar in both portal and peripheral blood. There were no significant changes in propionate concentrations after either dose of lactulose or sterile saline. Peak peripheral acetate concentrations were reached more rapidly after $6.7 \mathrm{~g}$ lactulose but the acetate concentrations remained higher for longer after $10 \mathrm{~g}$ lactulose.

\section{Discussion}

In the fasting state the origins of short chain fatty acids in portal and peripheral blood are several. In portal blood short chain fatty acids are principally derived from gut fermentation of colonic residues consisting of undigested food, mucus and proteins. ${ }^{4-18}$ This is in contrast with peripheral blood where acetate, the only readily measurable short chain fatty acid, is mainly endogenous in origin. ${ }^{+11} 11$ There is little or no endogenous release of propionate or butyrate into the peripheral circulation." There have been few studies in man which have followed the fate of short chain fatty acids, the major end products of the fermentation process. ${ }^{319.23}$ This is understandable given the difficulty of gaining access to both the human colon and portal vein in vivo. The present study reports the largest number of fasting portal short chain fatty acid measurements made in man. It is also the only in vivo study measuring portal short chain fatty acid concentrations after the direct instillation of fermentable carbohydrate into the human caecum. Fasting portal short chain fatty acid concentrations measured in the present study are similar to those measured by Dankert et $a l^{\prime \prime 1}$ in five patients also undergoing gall bladder surgery. Fasting peripheral short chain fatty acid concentrations measured in the present study are similar to those measured by Pomare $e t a l^{3}$ and Tollinger $e^{a} a^{22}$ but are slightly higher than those measured by Dankert et $a l^{21}$ who used serum rather than plasma and a different technique for the measurement of short chain fatty acids. The wide interindividual variation in fasting portal and peripheral short chain fatty acid concentrations found in the present study was also found by others. ${ }^{31122}$

In the fed state the major source of portal and peripheral short chain fatty acids is gut fermentation of dietary carbohydrate. ${ }^{102324}$ In the present study we have measured the change in portal and peripheral plasma short chain fatty acid concentrations after the caecal instillation of the disaccharide lactulose (O- $\beta$-D galactopyranosyl-1-4-D-fructofuranose), which escapes digestion in the small intestine but is broken down in the colon. ${ }^{25}$ Portal plasma short chain fatty acid concentrations, principally acetate, increased rapidly with peak concentrations after lactulose being reached in 15 to 45 minutes indicating rapid colonic fermentation of the lactulose and absorption of the resultant short chain fatty acids. Portal plasma acetate and propionate concentrations measured in the present study are less than those found in sudden death victims by Cummings et $a l^{23}$ but portal plasma butyrate concentrations are comparable. The doses of lactulose given in our study, however, were small and the quantity of undigested food present in the gut of the sudden death victims was considerable (average $291 \mathrm{~g}$ ). Peripheral plasma acetate concentrations also increased after caecal lactulose instillation but the increases were smaller and occurred more slowly than those measured in portal plasma. Peripheral plasma propionate and butyrate concentrations remained unchanged. The peripheral plasma acetate concentrations followed 10 $\mathrm{g}$ lactulose measured in the present study are comparable with those measured by Pomare et al. ${ }^{3}$

There were large differences between portal and peripheral short chain fatty acid concentrations, especially for propionate and butyrate, 
measured in the present study. In the fasting and fed state peripheral acetate concentrations were approximately $45 \%$ lower than portal acetate concentrations and peripheral concentrations of propionate and butyrate was $87-100 \%$ lower than portal concentrations. These differences have also been shown in the fasting state by Dankert $e t a l^{21}$ and in the fed state by Cummings et $a l^{23}$ The propionate and butyrate in portal blood would therefore appear to be virtually completely extracted by the liver ${ }^{102326}$ unlike acetate which is also delivered systemically to peripheral tissues where it is extensively metabolised especially in the fasting state. ${ }^{3+1018-20232829}$

In each subject (with one exception), the pattern of change in acetate concentration measured in peripheral blood mirrored that measured in portal blood. A slight time delay in the peripheral changes was seen in some subjects. Therefore, although the magnitude of the changes in acetate concentrations is larger in portal blood, peripheral blood measurements provide a reasonable reflection of the pattern of change. The same cannot be said for propionate and butyrate as the peripheral concentrations remained unchanged despite considerable increases in portal concentrations after lactulose.

The authors wish to thank Associate Professor R J Stewart, Department of Surgery, Wellington School of Medicine, Dr I
Bisset, Surgical Registrar, Wellington Hospital, Drs C Duffy, J Bisset, Surgical Registrar, Wellington Hospital, Drs C Duffy, J Malani, A Herbert, Gastroenterology Registrars, Wellington
Hospital, for their assistance in obtaining blood samples; the patients for consenting to take part in the study and secretaria staff for preparation of the manuscript. This project was supported by the Medical Research Council of New Zealand (Grant number $84 / 42,86 / 22$ ).

1 Cummings JH. Fermentation in the human large intestine: evidence and implications for health. Lancet 1983; i: 1206-8

2 Keys JE, Debarthe JV. Cellulose and hemicellulose digestibility in the stomach, small intestine and large intestine of swine. F Anim Sci 1974; 39: 53-6.

3 Pomare EW, Branch WJ, Cummings JH. Carbohydrate fermentation in the human colon and its relation to acetate concentrations in venous blood. $\mathcal{F}$ Clin Invest 1985; 75 1448-54.

4 Buckley BM, Williamson DH. Origins of blood acetate in the rat. Biochem $\mathcal{F}$ 1977; 166: 539-45.

5 Snoswell AM, Trimble RP, Fishlock RC, Storer GB, Topping DL. Metabolic effects of acetate in perfused rat liver. Studies on ketogenesis, glucose output, lactate uptake and lipogenesis. Biochim Biophys Acta 1982; 716: 290-7.

6 Siegel S, ed. Non-parametric statistics for the behavioural sciences. New York: McGraw-Hill Book Company, 1956.

7 Perman JA, Modler S. Glycoproteins as substrates for production of hydrogen and methane by colonic bacterial flora. Gastroenterology 1982; 83: 388-93.
8 Hoskins LC, Boulding ET. Mucin degradation in human colon ecosystems. Evidence for the existence and role of bacterial sub-populations producing glycosidases as extrabacterial sub-populations producing glycosidas
cellular enzymes. 7 Clin Invest $1981 ; 67: 163-72$.

9 Variyam EP, Hoskins LC. Mucin degradation in human colon ecosystems. Degradation of hog gastric mucin by fecal extracts and fecal cultures. Gastroenterology 1981;81:751-8.

10 Bergman EN. Production and utilisation of metabolites by the alimentary tract as measured in portal and hepatic blood. In IW McDonald, ACI Warner, eds. Digestion and metabolism in the ruminant. Proceedings of the IV International Symposium on Ruminant Physiology, Sydney, Australia: University of New England Publishing, 1975; 292-305.

11 Pethick DW, Lindsay DB, Barber PS, Northrop AJ. Acetate supply and utilisation by the tissues of sheep in vivo. $B r . \mathcal{Y}$ Nutr 1981; 46: 97-110.

12 Hoskins LC. Human enteric population ecology and degradation of gut mucins. Dig Dis Sci 1981; 26: 769-72.

13 Vercellotti JR, Salyers AA, Bullard WS, Wilkins TD. Breakdown of mucin and plant polysaccharides in the human colon. Can F Biochem 1977; 55: 1190-6.

14 Perman JA, Modler S. Hydrogen $\left(\mathrm{H}_{2}\right)$ and methane $\left(\mathrm{CH}_{4}\right)$ are products of glycoprotein catabolism by colonic flora. [Abstract]. Gastroenterology 1981; 80: 1251 .

15 Salyers AA, West SEH, Vercellotti JR, Wilkins TD Fermentation of mucins and plant polysaccharide by anaerobic bacteria from the human colon. Appl Environ Microbiol 1977; 34: 529-33.

16 Annison EF, White RR. Further studies on the entry rates of acetate and glucose in sheep with special reference to acetate and glucose in sheep with special reference to 52 .

17 Ballard FJ. Supply and utilisation of acetate in mammals. Am J Clin Nutr 1972; 25: 773-9.

18 Knowles SE, Jarrett IG, Filsell OH, Ballard FJ. Production and utilisation of acetate in mammals. Biochem $\mathcal{F} 1974 ; 142$ : 401-11.

19 Skutches CL, Holroyde CP, Myers RN, Reichard GA. Plasma acetate turnover and oxidation. $\mathcal{F}$ Clin Invest 1979; 64: 70813.

20 Seufert CD, Mewes W, Soeling HD. Effect of long-term starvation on acetate and ketone body metabolism in obese patients. Eur f Clin Invest 1984; 14: 163-70.

21 Dankert J, Zijlstra JB, Wolthers BG. Volatile fatty acids in human peripheral and portal blood: quantitative determination by vacuum distillation and gas chromatography Clin Chim Acta 1981; 110: 301-7.

22 Tollinger CD, Vreman HJ, Weiner MW. Measurement of acetate in human blood by gas chromatography: effects of sample preparation, feeding and various diseases. Clin Chem 1979; 25: 1787-90.

23 Cummings JH, Pomare EW, Branch WJ, Naylor CPE Macfarlane GT. Short chain fatty acids in human large intestine, portal, hepatic and venous blood. Gut 1987; 28: intestine,

24 Cummings JH, Englyst HN. Fermentation in the human large intestine and the available substrates. Am $\mathcal{f}$ Clin Nutr 1987 45: 1243-55.

25 Saunders DR, Wiggins HS. Conservation of mannitol lactulose, and raffinose by the human colon. Am $\mathcal{F}$ Physio 1981; 241: G397-402

26 Remesey C, Demigne C, Chartier F. Origin and utilisation of volatile fatty acids in the rat. Reprod Nutr Develop 1980; 20 1339-49.

27 Remesey C, Demigne C. Changes in availability of glucogenic and ketogenic substrates and liver metabolism in fed or starved rats. Ann Nutr Metab 1983; 27: 57-70.

28 Lindeneg $\mathrm{O}$, Mellemgaard $\mathrm{K}$, Fabricius $\mathrm{J}$, Lundquist $\mathrm{F}$. Myocardial utilisation of acetate, lactate and free fatty acids Myocardial utilisation of acetate, lactate and free fa

29 Lundquist F, Sestoft L, Damgaard SE, Clausen JP, Trap Jensen $\mathrm{J}$. Utilisation of acetate in the human forearm during exercise after ethanol ingestion. $\mathcal{F}$ Clin Invest 1973; 52: 32315 . 